American J. of Engineering and Applied Sciences 4 (3): 405-412, 2011

ISSN 1941-7020

(C) 2014 C.O. Osueke, This open access article is distributed under a Creative Commons Attribution

(CC-BY) 3.0 license

\title{
Frictional Impact Modeling of a Cereal Thresher
}

\author{
Christian Okechukwu Osueke \\ Department of Mechanical and Production, Faculty of Engineering, \\ Enugu State University of Science and Technology, Enugu, Nigeria
}

\begin{abstract}
Problem statement: There is no point producing cereal threshing models that cannot replicate its performance on the field. The frictional impact that occurs between the crop surface and threshing cylinder had been often neglected by most researchers in cereal threshing. Approach: Study proffers a solution to this issue by developing a model for threshing which in-cooperate friction. This was done by analyzing the crop/threshing cylinder behavior, hence establishing mathematical sub-models to characterize the performance of this model. Results: The model was further packaged with computer aided software based on visual basic programming language and finally applied. Conclusion: Upon application, it was discovered that at a moisture content of $15 \% \mathrm{v}=9 \mathrm{~m} \mathrm{sec}^{-1}, \mathrm{Q}=0.18 \mathrm{~kg} \mathrm{sec} \mathrm{se}^{-1}$ the model yielded performance characteristics as Eff $=88.22 \%, \mathrm{TNL}=11.78 \%$ and CAPTH $=211.52 \mathrm{~kg} \mathrm{~h}^{-1}$.
\end{abstract}

Key words: Cereal threshing, threshing cylinder, cooperate friction, sub-models, programming language, moisture content, model yielded, yielded performance, frictional model

\section{INTRODUCTION}

Unfortunately, a completely precise model of a physical system is not possible, thus there will always be model errors and uncertainties, but even if a model describes just a part of the reality it can be very useful for analysis and design if it describes the dominating dynamic properties of the system. Friction is a very complicated phenomenon arising at the contact of surfaces. In many engineering applications, the success of models in predicting experimental results remains strongly sensitive to the friction model. A cereal threshing system is not an exception in this consideration. The friction that occurs at the contact surface of the crop and the beater is an integral part of threshing though neglected by several researchers. This friction is as a result of the rubbing action which leads to the detachment of grains from their panicle and hence threshing occurs. To properly produce a frictional model for grain threshing, the friction factor alongside all other parameters based on physical characteristics of the crop and machine specification need to be incorporated in the modeling process. Very few researchers engaged this combination while some others neglected it.

According to Simonyan et al. (2009) report on Lablab Purpurusin grain, the grain mass, size and volume increased with increasing moisture content at a range of 9.7 to $29 \%$ web basis (w.b) for "rongai" variety and 10.2 to $22.6 \%$ (w.b) for "high worth" variety. They also reported that there was a decrease in bulkdensity with increasing moisture content at this same range. Olaoye and Oni (2001) found that the average threshing moisture content is $10.2 \%$ for millet and its average rupture force of $7.54 \mathrm{~N}$. Furthermore, Bolufani (2001) considered some physical and mechanical properties like moisture content, major and minor diameters, bulk density and angle of repose and grain/straw ratio. He used different feed rates of 20, 25, 40 and $50 \mathrm{~kg} \mathrm{~h}^{-1}$ at two moisture contents of 9.5 and $12.5 \%$. He observed that low moisture content increased threshing efficiency. Nwuba and Braide (1994) as reported by Ibeabuchi (2006), five sieves of sizes: 7, 8, 8.5, 9 and $10 \mathrm{~mm}$ with concave sizes of 8.5 and $10 \mathrm{~mm}$ were used for different grain sizes, feed rate of $20-30 \mathrm{~kg} \mathrm{~h}^{-1}$ and blower airflow of $486 \mathrm{~m}^{3} \mathrm{~min}^{-1}$; they suggested that low feed rate should be used to avoid clogging of the thresher. Ghaly (1985) reported that the machine capacity which he expressed as feed rate was affected by both the cylinder speed and the diameter of the chopping concave. When the cylinder speed was increased from 600-900 rpm and further increased from $900-1100 \mathrm{rpm}$, the capacity was found to increase and then decreased respectively. Asli-Ardeh et al. (2008) investigated the effcets of drum speed and moisture content of crop on threshing loss and damaged grain percent on an auto head feed threshing unit. They kept the drum speed at five levels and moisture content at two levels. The result showed that moisture content of crop and drum speed had significant effect on threshing loss with the optimum speed obtained at 650 r.p.m. They suggested it is better that threshing of paddy be conducted in wet condition. Asli-Ardeh et al. 
(2009) the effects of drum speed and crop moisture content on threshing loss and damaged grain percent were also evaluated for a single plant thresher. They discovered that the effect of crop moisture content was significant at probability level of $1 \%$ on the threshing loss. They also discovered that with increasing the drum speed, threshing loss decreased and at all speed levels, increasing it led to increased damaged grain percent.

As much as was available by study, Vas and Harison (1969) are the only researchers that developed a frictional model for threshing in which they studied the effect of selected mechanical parameters on kernel damage and threshing of wheat. They reported that within the limitations of variety and bulk density, the mechanical parameters causing significant variation in thresh ability are cylinder speed, concave clearance and feed rate. They described the effect of these three parameters on thresh ability and kernel damage firstly on the basis of "impact model" of which they proposed that an increased feed rate resulted in a decrease in thresh ability, since this proposal was not supported by the results, therefore a frictional model was developed. According to this model, increased feed rate increased the crop stream density which in turn increased the frictional forces between particles in the crop stream. Thus the cushioning effect of the impact model may have tended to decrease the thresh ability but was offset by the increased rubbing action of the frictional model.

The major challenge encountered with most models is their ability to replicate real live situations. If a thresher model is done without including the friction factor, the result of that model, when run would not replicate field results. This is because in real life threshing, friction is prevalent. Therefore to introduce a reliable thresher model that will compete and thrive in the threshing industry, the incorporation of friction factor is highly recommended.

Approach: Firstly, good information of the thresher to be developed and the procedure governing the model development is exposed and then a model design is carried out by establishing sub-mathematical models to describe the threshing process.

Thresher development: Threshing a grain from the panicle is done between a rotating cylinder and a stationary concave. Three different cylinders used for threshing different crops are the spike tooth, the rasp bar and the angle bar as in Fig. 1. In the spiketooth type, spikes are mounted on the periphery of the cylinder. Also in a raspbar type, corrugated bars are mounted axially on the periphery of the cylinder while in the angle bar type, cone shaped bars are mounted on the periphery of the cylinder at an angle of $60-70^{\circ}$. Addo et al. (2004) reported that while threshing soyabean, the rasp bar cylinder gave the lowest split loss of $0.68 \%$ as against $1.64 \%$ for spike tooth at $376 \mathrm{rpm}$ and $316 \mathrm{rpm}$ respectively and the germination loss was lowest at rasp bar cylinder speed of 316rpm.

For the purpose of this study, the rasp bar cylinder was adopted based on Addo et al. (2004) report and also because it provides more surface area for frictionl impact. The compartment housing the threshing cylinder and concave sieve is called the threshing chamber. The threshing cylinder is endowed with nomenclatures that form part of the machine physical characteristics that is used in forming the model to be developed. Figure 2 and 3 describes the threshing chamber and some associated parameters.

A total comprehension of the threshing chamber is necessary because the frictional modeling of the cereal thresher is based on what transpires within the chamber which is as a result of crop (panicle) and cylinder movement.

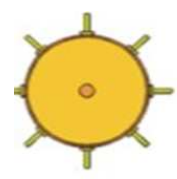

Spike tooth

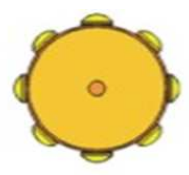

Rasp bar

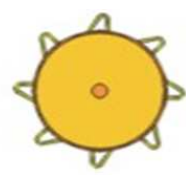

Angle bar
Fig. 1: Types of threshing cylinders (source: IRRI 2009)

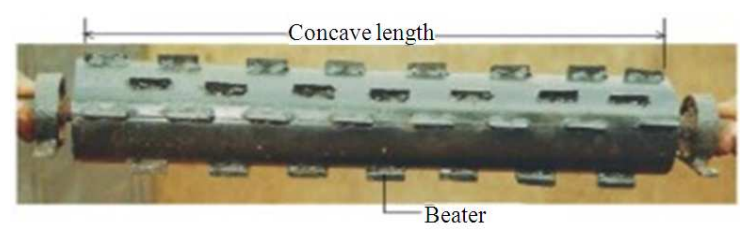

Fig. 2: The threshing drums showing the beater and concave length

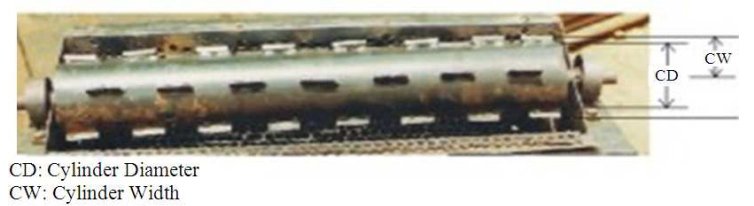

Fig. 3: The threshing chamber showing the cylinder diameter and cylinder width 
Model development: Part of the means of attaining success in modeling is by establishing a model structure. On establishing the model structure, operating conditions are set for the threshing operation and the fundamental mechanisms of the threshing system are better understood. Firstly the crop and machine variables that are needed to evaluate performance are identified. Secondly, a model structure is adopted whereby there is only one main program called the "main supervisor" while others exist as modules. This structure was adopted because the modules act as standalone system.

Model design: The threshing and separation which occurs within the threshing chamber can be divided into three stages.

- The detachment of grains from their panicle

- The migration of grains through the straw mat

- The penetration of grain through the concave opening

Since the friction between the crop and cylinder (beater) contributes to the execution of stage 1, therefore a detailed extrusion of this process need to be represented in the model design.

If the threshing cylinder precisely the beater is considered for frictional impact analysis, the detachment of a grain from the panicle takes place at three surfaces (A, C and D) by frictional impact as shown below (Fig. 4).

Direct impact takes place only at surface B which had been discussed in Osueke (2011) under the caption: direct impact model. In Fig. 5 the threshing cylinder (beater) rotates about two frictionless points (bearings) and one of these points is labeled $\mathrm{O}$ when viewed from the end elevation.

The threshing drum is designed in such a way that panicles are introduced through the hopper into the threshing drum at an offset from the line of center of the threshing drum and falls by gravity as shown in Fig. 6 .

Analyzing the threshing process for frictional impact and considering the normal frictional force at the instant where the panicle is hit by the beater at location point $(\mathrm{a}, \mathrm{b})$ which is relative to location point $\mathrm{O}$ as shown in Fig. 7.

Let the initial angular velocity of the beater just before the impact be $\omega_{1}$ while $\omega_{2}$ represent its angular velocity immediately after frictional impact of time durationt $_{1}$. By the impulsive principle Eq. 1:

$$
\mathrm{J}_{0} \omega_{1}+\underset{\mathrm{o}}{\mathrm{O}_{1}}(\mathrm{Na}+\mathrm{Fb}) \mathrm{dt}=\mathrm{J}_{0} \omega_{2}
$$

where, $\mathrm{J}_{0}$ is the beaters moment of inertia about $0, \mathrm{~N}$ and $\mathrm{F}$ are the normal and frictional force acting on the beater at the point of contact with the rough surface of the panicle.
Following Keller (1986), the unknown time variation of the normal force $\mathrm{N}(\mathrm{t})$ can be eliminated from the analysis by introducing a monotonically increasing impulse parameter $\mathrm{T}$ as Eq. 2 :

$$
\Gamma=\stackrel{\mathrm{o}}{\mathrm{t}}_{0}^{\mathrm{Ndt}}, \mathrm{d} \Gamma=\mathrm{Ndt}
$$

Onward further simplification:

$$
\mathrm{J}_{0}\left(\omega_{2}-\omega_{1}\right)=\mathrm{aW}+\mathrm{b}_{0}^{\mathrm{W}} \frac{\mathrm{F}}{\mathrm{N}} \mathrm{dW}
$$

let $0<\mathrm{W}_{0}<\mathrm{W}_{1}$ : corresponds to the instant $\mathrm{t}_{0}$ when the angular velocity momentarily changes at the instance when the panicle is enclose contact with the beater and the slip reversal takes place on the panicle at the transition between the compression and restitution phases of the impact. Assuming that during the impact the tangential component of the reactive force is related to the normal component by the Amnions Coulomb law of sliding (dry) friction and ignoring the tangential compliance of the colliding bodies, we can write:

$$
\frac{\mathrm{F}}{\mathrm{N}}=-\mu \operatorname{sign}(\omega)=-\mu \operatorname{sign}\left(\mathrm{W}-\mathrm{W}_{0}\right)
$$

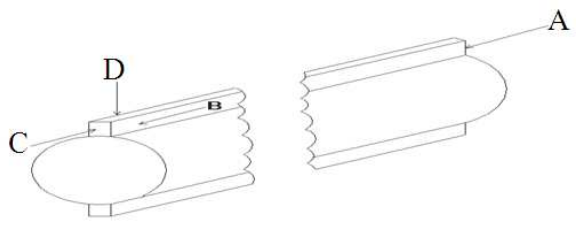

Fig. 4: Threshing drum showing the surfaces A, B, C, D

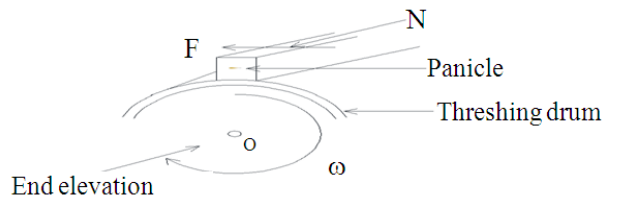

Fig. 5: Threshing cylinder showing frictionless point o, panicle, normal reaction $\mathrm{N}$, frictional force $\mathrm{F}$ and angular velocity of the beater $\omega$

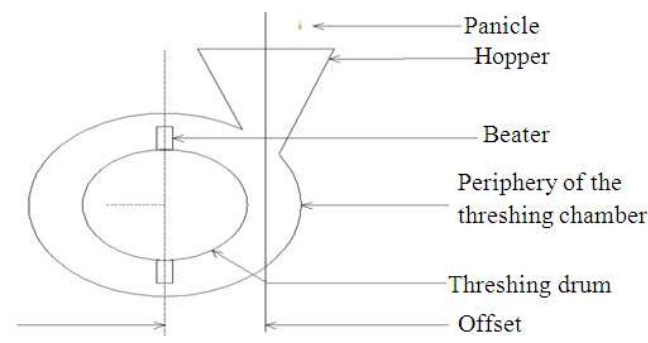

Fig. 6: The diagram shows the offset positioning of the hopper on the threshing drum 


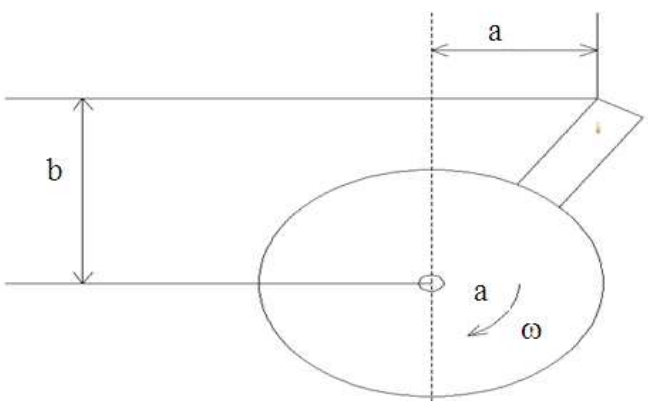

Fig. 7: Beater with location points a and $b$

where, $\mu$ is the coefficient of kinetic friction? The substitution Eq. 4 into 3 upon integration, gives Eq. 4:

$\omega=\frac{\mathrm{a}-\mu \mathrm{b}}{\mathrm{J}_{0}}\left(\mathrm{~W}-\mathrm{W}_{0}\right), \mathrm{W}_{0} \leq \mathrm{W} \leq \mathrm{W}_{1}$

The normal impulse $\omega_{0}$ determined from the condition $\omega\left(\mathrm{W}_{0}\right)=0$, is obtained from the first equation in Eq. 5 and 6 as:

$\mathrm{W}_{0}=\frac{\mathrm{J}_{0} \omega_{1}}{\mathrm{a}+\mu \mathrm{b}}$

In order that $\omega>0$ in the interval $\left(\mathrm{W}_{0}, \mathrm{~W}_{1}\right)$, the coefficient of kinetic friction must be bounded by $\mu<\mathrm{a} / \mathrm{b}$. If $\mu<\mathrm{a} / \mathrm{b}$, the panicle sticks to the beater after the impact with no rebounding velocity. The angular velocity expression (Eq. 5) can be rewritten in a bilinear form as shown below Eq. 7:

$\omega=\frac{\mathrm{a}-\mu \mathrm{b}}{\mathrm{a}+\mu \mathrm{b}}\left(1-\frac{\mathrm{W}}{\mathrm{W}_{0}}\right) \omega_{1}, \mathrm{~W}_{0} £ \mathrm{~W} £ \mathrm{~W}_{1}$

The total normal $\mathrm{W}_{1}$ is still an unknown quantity in the analysis and cannot be determined without further assumptions. To proceed, we introduce the coefficient of normal restitution by the Poisson definition as the ratio of the normal impulses corresponding to restitution and compression phases of the impact, i.e., Eq. 8:

$\mathrm{k}=\frac{\mathrm{W}_{1}-\mathrm{W}_{0}}{\mathrm{~W}_{0}}>0, \mathrm{~W}_{1}=(1+\mathrm{k}) \mathrm{W}_{0}$

The angular velocity $\omega_{2}=\omega\left(\mathrm{W}_{1}\right)$ of the beater when the panicle rebounds is related to the incidence angular velocity by Eq. 9: $\omega_{2}=-k \frac{a-\mu b}{a+\mu b} \omega_{1}$

With this, the angular velocity during the restitution phase of the impact can be written, from Eq. 7, as Eq. 10:

$\omega=\frac{1}{\mathrm{k}}\left(1-\frac{\mathrm{W}}{\mathrm{W}_{0}}\right) \omega_{2}, \mathrm{~W}_{0} \leq \mathrm{W} \leq \mathrm{W}_{1}$

Introducing the horizontal and vertical velocity components of the contact point during the impact, $\mu=$ b $\omega$ and $v=\alpha \omega$, Eq. 10 can be rewritten as Eq. 11:

$\mathrm{v}_{2}+\mu \mathrm{u}_{2}=-\mathrm{k}\left(\mathrm{v}_{1}-\mu \mathrm{u}_{1}\right)$

For the panicle to rebound $\omega_{1}$ of the beater and $\omega_{2}$ of the panicle (which is equal to or greater than $\omega_{2}$ ) have to be of opposite sign. Where $\omega_{2}$ is the velocity of the panicle after impact with beater.

The kinetic energy dissipated by the frictional impact is Eq. 12-14:

$\square \mathrm{E}=\mathrm{E}_{1}-\mathrm{E}_{2}=\frac{1}{2} \mathrm{~J}_{0}\left[\left(\omega_{1}\right)^{2}-\left(\omega_{2}\right)^{2}\right]=\frac{1}{2}\left(1-\hat{\mathrm{k}}^{2}\right) \mathrm{J}_{0}\left(\omega_{1}\right)^{2}$

This energy can be cast in the form of the generalized Thompson Tait formula (Brogliaoto, 1999; Osueke, 2011) i.e.:

$\square E=-\frac{1}{2} f_{1}\left(u_{1}+u_{2}\right)-\frac{1}{2} T_{1}\left(v_{1}-v_{2}\right)$

Indeed from Eq. 15, one can write $\mathrm{aT}_{1}+\mathrm{bf}_{1}=-\mathrm{J}_{0}\left(\omega_{1}-\omega_{2}\right)$ so that:

$\square \mathrm{E}=\frac{1}{2} \mathrm{~J}_{\mathrm{o}}\left(\omega_{1}-\omega_{2}\right)\left(\omega_{1}+\omega_{2}\right)=-\frac{1}{2}\left(\mathrm{aT}_{1}+\mathrm{bF}_{1}\right)\left(\omega_{1}+\omega_{2}\right)$

Since $\mu=b \omega$ and $v=\alpha \omega$

Having established the frictional impact mathematical model, a proper threshing process model can now be generated.

Mathematical modeling of the threshing stage: Ndirika (1994) describe this stage of threshing as that of impact which detaches a grain from straw mat binding. This is actually the most important stage of threshing and must be modeled properly. Considering 
Am. J. Engg. \& Applied Sci., 4 (3): 405-412, 2011

firstly the energy transferred to the panicle from the beater, if the mass flow rate of panicle (feed rate) $=\mathrm{Qkg}$ $\sec ^{1}$ and rise in kinetic energy of panicle with each impact per unit mass of panicle is equal to $\frac{1}{2} \mathrm{v}^{2}$. Then the rate of transfer of kinetic energy to the panicle by the beater is $\frac{\mathrm{Qv}^{2}}{2}$. Tagging the energy to dislodge grain from panicle as $E_{g}$ the rate of detachment of grain becomes:

$$
\frac{\mathrm{Qv}_{\mathrm{b}}^{2}}{2 \mathrm{E}_{\mathrm{g}}}=\lambda
$$

The total energy balance along the beater is a summation of the energy as a result of direct impact $\left(\mathrm{E}_{\mathrm{dir}}\right)$ and frictional impact $\left(\mathrm{E}_{\mathrm{fr}}\right)$. i.e, Eq. 16:

$$
\mathrm{E}_{\mathrm{g}}=\mathrm{E}_{\mathrm{fr}}+\mathrm{E}_{\mathrm{dir}}
$$

From Eq. 14, $\mathrm{E}_{\mathrm{fr}}$ is represented as:

$$
\begin{aligned}
& \mathrm{E}_{\mathrm{fr}}=-\frac{\mathrm{K}_{\mathrm{E}}}{2}\left(\mathrm{aT}_{1}+\mathrm{bF}_{1}\right)\left(\omega_{1}+\omega_{2}\right)=-\frac{\mathrm{K}_{\mathrm{E}}}{2}\left(\mathrm{aT}_{1}+\mathrm{bF}_{1}\right)\left(2 \omega_{1}\right) \\
& \left\{\omega_{1}=\omega_{2} \text { after impact }\right\}
\end{aligned}
$$

The collision between the grain and threshing drum is an elastic one. Hence $\mathrm{W}_{1}=1$ and $\mathrm{F}_{1}=\mu \mathrm{N}$ and upon substitution into Eq. 17:

$$
\mathrm{E}_{\mathrm{fr}}=-\mathrm{K}_{\mathrm{E}}(\mathrm{a}+\mathrm{b} \mu \mathrm{N})\left(\omega_{1}\right)=-\mathrm{K}_{\mathrm{E}}(\mathrm{a}+\mathrm{b} \mu \mathrm{N})\left(\frac{\mathrm{v}}{\mathrm{w}}\right)
$$

(where $\mathrm{w}=$ cylinder width $\}$

To account for energy as a result of direct impact, the idea of Huynh et al. (1982) is adopted further developed because it contains the required parameters for modeling. In line with this, the specific energy as a result of direct impact needed for threshing can be considered to be directly proportional to a function of velocity ( $v)$, concave clearance (c), bulk density (p) and feed rate (Q), i.e. Eq. 19:

$$
\mathrm{E}_{\mathrm{i}} \propto \mathrm{f}(\mathrm{v}, \mathrm{c}, \rho, \mathrm{Q})
$$

Using rayleighs indicial method of dimensional analysis and further simplification, $\mathrm{E}_{\mathrm{i}}$ is uncovered and converted to energy thus:

$$
\mathrm{E}_{\mathrm{i}}=\mathrm{K}_{\mathrm{E}}\left(\frac{\mathrm{vQ}}{\mathrm{c}^{2} \rho}\right) ; \mathrm{E}_{\mathrm{dir}}=\mathrm{K}_{\mathrm{E}}\left(\frac{\mathrm{mvQ}}{\mathrm{c}^{2} \rho}\right)
$$

Substituting Eq. 20 and 18 into Eq. 17, E $\mathrm{g}_{\mathrm{g}}$ becomes:

$$
\mathrm{E}_{\mathrm{g}}=\mathrm{K}_{\mathrm{E}}\left[\left(\frac{\mathrm{mvQ}}{\rho c^{2}}\right)-\left[(\mathrm{a}+\mathrm{b} \mu \mathrm{N})\left(\frac{\mathrm{v}}{\mathrm{w}}\right)\right]\right]
$$

Substituting Eq. 21 for $\mathrm{E}_{\mathrm{g}}$ in Eq. 15, the mean threshing rate becomes Eq. 22:

$$
\lambda=\mathrm{K}_{\mathrm{f}} \frac{\mathrm{vec}^{2}}{2\left[\mathrm{~m}-\left[(\mathrm{a}+\mathrm{b} \mu \mathrm{N})\left(\frac{\rho c^{2}}{\mathrm{Qw}}\right)\right]\right]}\left\{\text { where } \mathrm{K}_{\mathrm{f}}=\frac{1}{\mathrm{~K}_{\mathrm{E}}}\right\}
$$

Development of sub-models (threshing efficiency, threshing loss and thresher capacity): The submodels characterize the performance of the model and hence need to be developed.

The threshing efficiency sub-model is given by:

$$
\text { Eff }=1-e^{-K_{f}} \frac{\mathrm{vpc}^{2}}{2\left[Q v-\left[(a+b \mu N)\left(\frac{c^{2}}{Q w}\right)\right]\right]}
$$

To introduce the moisture content parameter into the model, Islam and Pederson (1987) report of threshing being done at $10-25 \%$ is taken up. The relationship between moisture content and density is therefore proposed to be:

$\rho=\frac{1}{0.15}\left[0.25 \rho_{10}-0.1 \rho_{25}-\alpha\left(\rho_{10}-\rho_{25}\right)\right]\{\alpha=$

Substituting Eq. 24 for $\rho$ in Eq. 23, the threshing efficiency sub-model becomes Eq. 25-27:

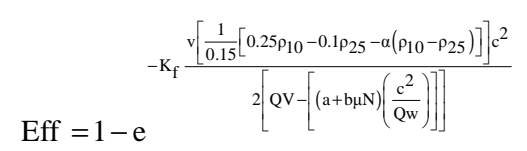

The threshing loss sub-model is also given by:

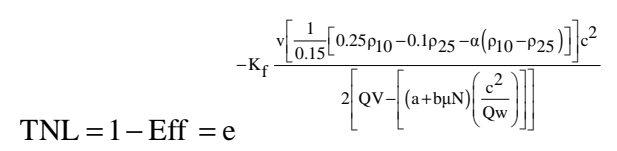

The thresher capacity sub-model is finally given by:

$\mathrm{CAPTH}=\mathrm{Eff} * \mathrm{Q}^{*} \delta \quad\{$ where $\delta$ is the length of straw mat $\}$ 
Am. J. Engg. \& Applied Sci., 4 (3): 405-412, 2011

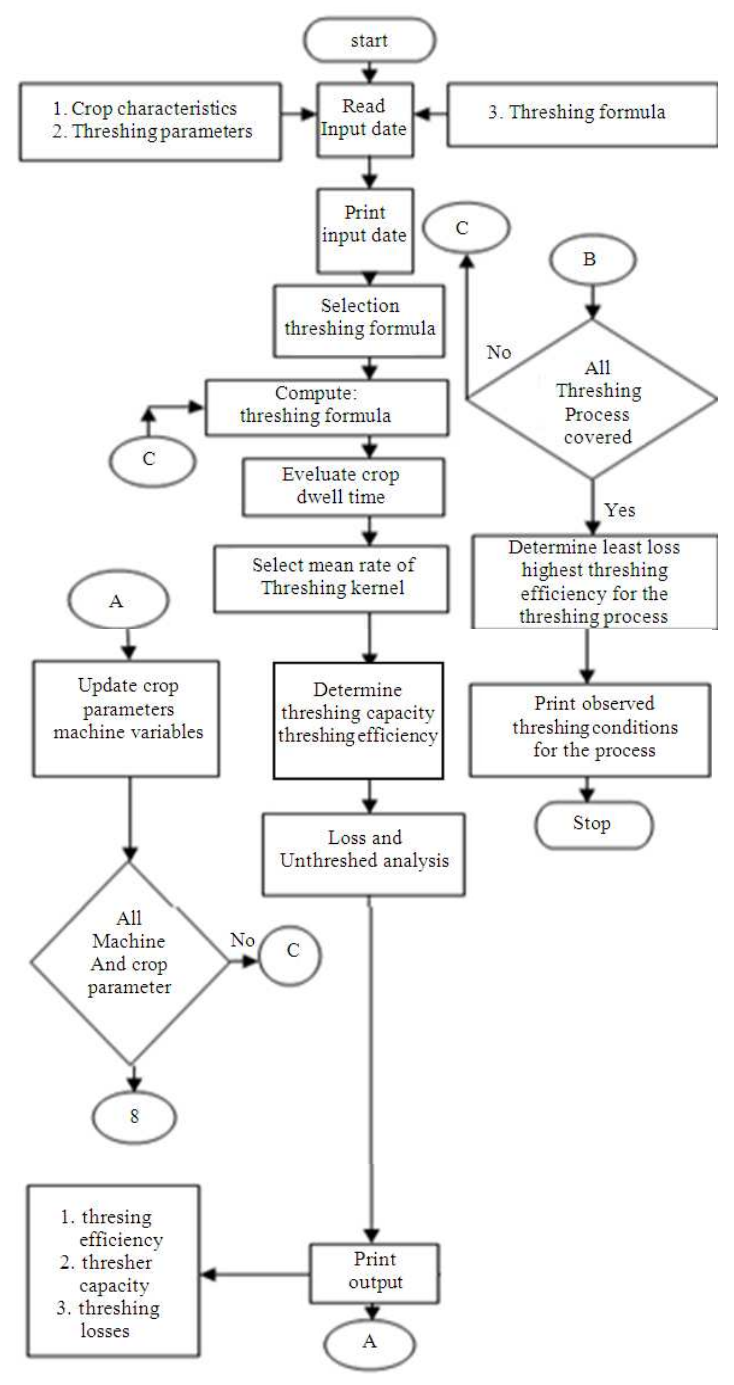

Fig. 8: Flow chart of the model packaging process

\section{MATERIALS AND METHODS}

The basic tool for the model development is the computer aided software written in visual basic programming language. Mathematical sub-models were used to develop the computer program. The model packaging was done in such a way that it involved 3 different steps:

- General design principles for the package

- Structure and

- Implementation

Function of various modules processing these three steps empowers the model to perform its set out role which is to run a task in which machine and crop parameters are varied and adjusted, then the results of performance characteristics displayed.

This process is shown in Fig. 8.
Table 1: Machine parameters and their range of variation

\begin{tabular}{ll}
\hline Parameters & Dimension $(\mathrm{m})$ \\
\hline Cylinder diameter, D & $0.33 ; 0.36 ; 0.39 ; 0.43 ; 0.46 ; 0.5$ \\
Cylinder width, w & $0.15 ; 0.175 ; 0.190 ; 0.220 ;$ \\
& $0.250 ; 0.285$ \\
$\begin{array}{l}\text { Concave length, } \mathrm{L} \\
\begin{array}{l}\text { Coordinate point of impact on } \\
\text { the beater resolved along X-axis, b }\end{array}\end{array}$ & 0.7 \\
$\begin{array}{l}\text { Coordinate point of impact on } \\
\text { the beater resolved along Y-axis, b }\end{array}$ & 0.13 \\
$\begin{array}{l}\text { Center line distance between } \\
\text { adjacent concave bar } \mathrm{b}_{1}\end{array}$ & 0.002 \\
\hline
\end{tabular}

Table 2: Crop parameters and their variation

\begin{tabular}{ll}
\hline Parameters & Value/level \\
\hline Feed rate, Q $(\mathrm{kg} / \mathrm{s})$ & $0.02 ; 0.08 ; 0.12 ; 0.14 ; 0.19 ; 0.23$ \\
Bulk density, $\mathrm{r}\left(\mathrm{kg} \mathrm{m}^{-3}\right)$ & $4.9 ; 5.9 ; 6.8 ; 7.9 ; 9.8 ; 11.9$ \\
Moisture content, c $(\%)$ & 15 \\
Kernel diameter, d(m) & 0.0038 \\
Concave clearance, c(m) & $0.01 ; 0.15 ; 0.02 ; 0.025 ; 0.03 ; 0.035$ \\
Cylinder speed, v(m/s) & $9,11,15,18,20,24$ \\
\hline
\end{tabular}

Based on study and comparison made from works of past researchers, the machine parameters, crop parameters and constants were selected: Table 1 and 2 .

\section{RESULTS}

When the machine parameters are inputted into the model and then "run", results based on the mathematical representations of the sub-models are displayed. These results describe the performance of the frictional model so far developed. Figure 9 shows the result of the model when run within the moisture content bounds of $15 \%$ respectively.

The result from the developed frictional model shows that at a moisture content of $15 \%$, with inputs as:

$$
\begin{aligned}
& \mathrm{v}=\frac{9 \mathrm{~m}}{\mathrm{~s}}, \mathrm{Q}=\frac{0.18 \mathrm{~kg}}{\mathrm{~s}}, \mathrm{c}=0.02, \rho=\frac{4.9 \mathrm{~m}}{\mathrm{~s}}, \mathrm{w}=0.19, \\
& \mathrm{r}=0.37, \mathrm{~L}=0.7 \mathrm{~m}, \mathrm{~b}=0.13 \mathrm{~m}, \mathrm{a}=0.07 \mathrm{~m} \\
& \mathrm{D}=0.39, \mathrm{~N}=102 \mathrm{~N}, \mu=0.35
\end{aligned}
$$

The model yielded performance characteristics as:

$$
\text { Eff }=88.22 \%, \mathrm{TNL}=11.78 \% \& \mathrm{CAPTH}=211.52 \mathrm{~kg} / \mathrm{hr}
$$

This exact representation of field results.

\section{DISUCSSISON}

A thorough study of the result from the model output shows that there exists some relationship between the crop/machine parameters and the perfromance of the model. 


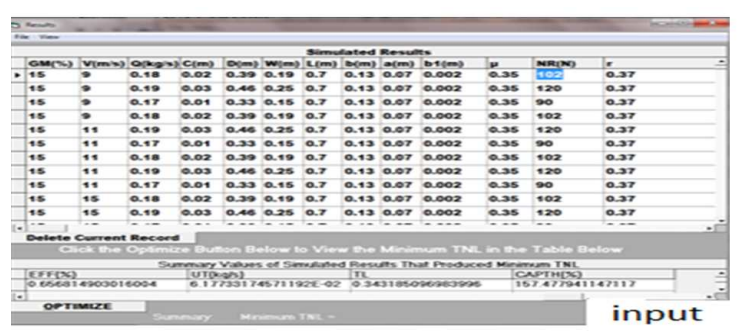

(a)

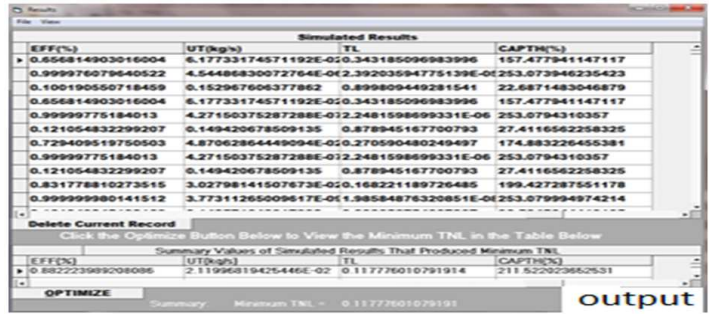

(b)

Fig. 9: (a) Input display (b): Output display of the frictional model when run

It was discovered that:

- When feed rate increases, threshing efficiency decreases while threshing loss increases. This is because as feed rate increases, more grains cluster within the threshing drum which reduces the chances of individual grains getting in contact with the surface area available for frictional impact and this cushioning effect reduces efficiency

- As the velocity increases, the threshing efficiency and capacity increases while the threshing losses reduces. This can probably be explained on the basis that frictional impact which contributes to threshing occurs at a faster rate when the cylinder speed increases

- Decreasing the concave clearance resulted in increased threshing efficiency and thresher capacity while an increase in concave clearance led to an increase in threshing losses. Decreasing the concave clearance may have increased the chance of a grain being struck by the bar and increased the chance of multiple direct and frictional impact to the grain before leaving the threshing chamber

\section{CONCLUSION}

Developing a frictional model for cereal threshing is a task that is really worth embarking on. This is because if a thresher is developed based on a nonfrictional model, the performance of such a thresher won't represent the model result. This implies that most models developed by researchers are false models. An actual (true) model is that developed based on friction which occurs within the threshing chamber and between the threshing cylinder and crop.

The model was made feasible by establishing submodels to characterize performance. This sub-model goes a long way to tell the efficiency of the thresher, losses in threshing and capacity of the thresher. These sub-models are:

- Threshing

efficiency

$$
\begin{aligned}
& \text { Eff }=1-\mathrm{e}^{-\mathrm{Kf}} \\
& \frac{\mathrm{v}\left[\frac{1}{0.15}\left[0.25 \rho_{10}-0.1 \rho_{25}-\alpha\left(\rho_{10}-\rho_{25}\right)\right]\right] \mathrm{c}^{2}}{2\left[\mathrm{QV}-\left[(\mathrm{a}+\mathrm{b} \mu \mathrm{N})\left(\frac{\mathrm{c}^{2}}{\mathrm{Qw}}\right)\right]\right]}
\end{aligned}
$$

- Threshing

loss

$$
\begin{aligned}
& \mathrm{TNL}=1-\text { Eff }=\mathrm{e}^{-\mathrm{Kf}} \\
& \frac{\mathrm{v}\left[\frac{1}{0.15}\left[0.25 \rho_{10}-0.1 \rho_{25}-\alpha\left(\rho_{10}-\rho_{25}\right)\right]\right] \mathrm{c}^{2}}{2\left[\mathrm{QV}-\left[(\mathrm{a}+\mathrm{b} \mu \mathrm{N})\left(\frac{\mathrm{c}^{2}}{\mathrm{Qw}}\right)\right]\right]}
\end{aligned}
$$

- $\quad$ Thresher capacity $\mathrm{CAPTH}=\mathrm{Eff} * \mathrm{Q} * \delta$

Packaging the model with computer aided software on "visual basic" programming language which makes the model interactive. On application of the model, its performance as described by the performance characteristics (Eff, TNL and CAPTH) is a true representation of real life threshing. This model can be adopted by industrialists and farmers who wish to embark on cereal threshing merchandise and services.

\section{ACKNOWLEDGEMENTS}

I am graciously thankful to Prof, E.I.E. Ofodile, Prof, Prof, O.C. Iloeje, Dr. N.O. Ibekwe for their immense support towards the actualization of study. Thanks also to Pastor Felix Aguboshi, head of department, Computer Science, Federal Polytechnic Oko, Anambra State Nigeria for assistance in statistical analysis.

\section{REFERENCES}

Addo, A., A. Bart-Plange, R.A. Asuboah and K. Dzisi, 2004. Effect of different threshing cylinders on soybean quality. J. Sci. Technol., 24: 121-125. 
Asli-Ardeh, E.A. and Y. Abbaspour-Gilandeh, 2008. Investigation of the effective factors on threshing loss, damaged grains percent and material other than grain to grain ratio on an auto head feed threshing unit. Am. J. Agric. Biol. Sci., 3: 699-705. DOI: 10.3844/ajabssp.2008.699.705

Asli-Ardeh, E.A., Y. Abbaspour-Gilandeh and S. Abbasi, 2009. Study of Performance Parameters of Threshing Unit in a Single Plant Thresher. Am. J. Agric. Biol. Sci., 4: 92-96. DOI: 10.3844/ajabssp.2009.92.96

Bolufani, S.J., 2001. Performance evaluation of pedal operated cowpea thresher. Proc. NIAE, 23:65-70.

Brogliaoto, B., 1999, Nonsmooth Mechanics: Models, Dynamics and Control. 2nd Edn., Springer Verlag, London, ISBN: 1852331437, pp: 552.

Ghaly, A.E., 1985. A stationary threshing machine: Design. Construction and performance evaluation. Mechanization Asia, Africa Latin Am., 16: 19-30.

Huynh, V.M., T. Powell and J.N. Siddal, 1982. Threshing and separation process: A mathematical model. Trans A.S.A.E., 25: 65-73.

Islam, N. and T.T. Pedersen, 1987. Some physical properties of wheat and paddy and their relationships. Mechanization Asia, Africa Latin Am., 18: 45-50.
Ibeabuchi, 2006. Design of multicrop thresher. Agric. Eng. Esut.

Keller, J.B., 1986. Impact with friction. ASME J. Apply Mech., 53: 1-4.

Ndirika, V.I.O., 1994. Development and performance evaluation of a millet thresher. J. Agricult. Eng. Technol., 2: 83-88

Nwuba, A.I.U. and F.G. Braide, 1994. Development of whole crop cowpea thresher as effected by grain and stalk properties. J. Agric. Eng. Technol. 2: 67-69.

Olaoye, J.O. and K.C. Oni, 2001. Some physical and mechanical properties of selected grain crops. Proc. NIAE., 23: 15-329.

Osueke, C.O., 2011. Simulation and Optimization modeling of performance of a cereal thresher. Int. J. Eng. Technol, 11: 143-152.

Simonyan, K.J., Y.D. Yiljep, O.B. Oyatoyan and G.S. Bawa, 2009. Effects of moisture content on some physical properties of Lablab purpureus (L.) sweet seeds. Agric. Eng. Int.: CIGR J. Manuscript, 11: 113.

Vas, F.M. and H.P. Harison, 1969. The effect of selected mechanical threshing parameters on kernel damage and threshibility of wheat. Canadian Agric. Eng., 11: 88-87. 